\title{
Comparative study of post-operative visual outcome and complications after small incision cataract surgery in patients of diabetic and non- diabetic patients of cataract
}

\author{
KekanA. ${ }^{1}$, Raut $\mathbf{S}^{2}$ \\ ${ }^{1}$ Dr. Aparna Kekan, Assistant Professor, Department of Ophthalmology, Parul Institute of Medical Sciences and \\ Research, Vadodara, ${ }^{2}$ Dr. Snehal Raut, Ophthalmology, Raut Nursing Home, Nagpur, Maharashtra, India.
}

Corresponding Author: Dr. Aparna Kekan, Assistant Professor, Department of Ophthalmology, Parul Institute of Medical Sciences and Research, Vadodara, India. E-mail: aparna_kekan@yahoo.com

\begin{abstract}
Objective: The purpose of the study was to compare post-operative visual outcome and complications after small incision cataract surgery (SICS) in diabetic and non-diabetic patients of cataract. Method: This was prospective comparative study of 60 patients having diabetes and 60 patients having cataract with no diabetes mellitus undergoing SICS. All patients underwent complete ocular examination including best corrected visual acuity, slit lamp bio microscopy, and $90 \mathrm{D}$ examination preoperative and postoperatively at 1 week, 4 week, 6week, 2 months, 6 months interval. Intraoperative and postoperative complications and best corrected visual acuity were noted. Result: Mean of best corrected visual acuity postoperatively was $6 / 36$ in diabetic patients while it was $6 / 6$ in non-diabetic patients. Patients with no retinopathy in diabetic group improved to 6/12-6/9, in non-proliferative diabetic retinopathy (NPDR) without maculopathy to $6 / 12-6 / 18$, NPDR with maculopathy improved to $6 / 36$, cases with proliferative diabetic retinopathy (PDR) with maculopathy had vision finger counting close to face and patients with PDR without maculopathy had vision 5/60-6/60. This value is statistically significant $\mathrm{p}=0.022$. suggesting worsening of visual outcome after small incision cataract surgery in diabetic patients due to diabetic retinopathy. Also, postoperative complications were noticed more in diabetic patients than anothernon-diabetic group who underwent SICS. Conclusion: SICS is a safe procedure in diabetic patients and decreased vision is attributed to preoperative diabetic retinopathy and worsening of diabetic retinopathy after small incision cataract surgery and not with the procedure per se. Visual acuity are almost same in diabetes and non- diabetes except for late stage. Complications are found more in diabetic patients.
\end{abstract}

Keywords: Small incision cataract surgery, Diabetes mellitus, Visual outcome, Complications

\section{Introduction}

Diabetes mellitus (DM) is one of the most prevalent non-communicable disease in the world and threat to public health. The chronic hyperglycemia of diabetics is associated with long term damage, dysfunctionand failure of various organs kidneys,nerves, heart,blood vessels and eyes.

DM can lead to several ocular complications such as diabetic retinopathy, diabetic papillopathy, glaucoma, cataract, and ocular surface diseases[1]. In older patients ocular symptoms are mainly of cataract others include refractive changes and retinopathy. Cataract surgeries are often carried out earlier amongst

Manuscript received: $10^{\text {th }}$ August 2018

Reviewed: $20^{\text {th }}$ August 2018

Author Corrected: $28^{\text {th }}$ August 2018

Accepted for Publication: $1^{\text {st }}$ September 2018
Diabetics [2]. Cataracts are disproportionately more likely to occur and their surgical correction more problematic in diabetic than in nondiabetic patients $[3,4]$. Although newer techniques like phacoemulsification have made cataract surgery safe and predictable [5] in developing nations small incision cataract surgery is common procedure carried out as being more economical and with almost similar clinical outcome in terms of vision and complications [6].

We believe that small incision cataract surgery is as good as phacoemulsification even in diabetics patients. In view of above things, the purpose of the study isto compare the postoperative complications and visual outcome after small incision cataract surgery in diabetic patients as compared to normal individuals with cataract 
who underwent small incision cataract surgery.We assessedthe visual outcome and postoperative complications in patients who were admitted for small incision cataract surgery in diabetic and diabetic non-diabetic patients in ophthalmology department of Parul Institute of Medical Sciences and Research, Vadodara.

\section{Materials and Methods}

This study was conducted in Parul Institute of Medical Sciences and Research, Vadodara from Oct 2015 to Aug 2017.

This study was a prospective, comparative study and method of sampling was convenient sampling. A total of 60 patients who were admitted with diminished vision due to cataract and found to be either known case of diabetes mellitus or detected to be diabetic during preoperative work up and rest of 60 pts having cataract with no systemic history were screened for inclusion and exclusion criteria.

Inclusion criteria-Patients of either sex, between 40 to 80 years of age group, who were diagnosed with unilateral or bilateral senile cataract mature/ immature, nuclear/cortical, diagnosed clinically, ophthalmoscopically and with help of slit lamp biomicroscopy examination were included in the study. Laboratory tests are included to rule out diabetes and then patients are divided into diabetic and non-diabetic category.
Exclusion criteria- Cataract patients at extremes of ages i.e before 40 and after 80 years of age, juvenile onset diabetes mellitus, lens induced glaucoma, previous surgery for glaucoma, psedoexfoliation syndrome, subluxated lens, uveitis, scleritis and high degree of refractive error were excluded from study.

All patients underwent complete ocular examination including best corrected visual acuity, slit lamp biomicroscopy examination, intraocular pressure, fundus examination including 90D and indirect ophthalmoscopy. Preoperative patients were classified as non-proliferative diabetic retinopathy with and without macular edema and proliferative diabetic retinopathy with and without macular edema (EDTRS classification). and those with absolutely normal fundus. All patients underwent small incision cataract surgery and Preoperative and intraoperative complications were noted. Patients followed up 1 week, 4 week, 6 week, 2 months and 6 months interval. A complete ocular examination was performed at each visit with postoperative vision noted and fundus changes are documented in patients of diabetes

Statistical analysis: For data analysis Epi info version 7.0 software were used. Proportions and mean were calculated. Chi square test and Fischer exact test were applied as test of significance for qualitative data. Significance was tested at 0.05 level.

\section{Result}

Total of 60 diabetic patients were present in study of which 21 were male (35\%) and $39(65 \%)$ were female with female to male ratio 1.9:1. In rest of patients with cataract with no DM 27 Male and 33 females, with female to male ratio 1:0.81.

There were 36 cases who were diagnosed to have diabetic retinopathy of which 5 cases were diagnosed to have nonproliferative diabetic retinopathy (NPDR) with macular edema (ME) (13.89\%), 20 (55.5\%) cases were diagnosed to have non-proliferative diabetic retinopathy without macular edema, $2(5.55 \%)$ cases of proliferative diabetic retinopathy (PDR) with macular edema and $9(25 \%)$ were proliferative diabetic retinopathy without macular edema.

Table 1: Showing severity of diabetic retinopathy preoperatively.

\begin{tabular}{|c|c|c|}
\hline Severity & Number & Percentage \\
\hline NPDR with ME & 5 & 13.89 \\
\hline NPDR without ME & 20 & 55.5 \\
\hline PDR with ME & 2 & 5.55 \\
\hline PDR without ME & 9 & 25 \\
\hline
\end{tabular}

In 28 cases less than 60 years of age group who showed improvement in visual acuity were 11(39.3\%) and those who deteriorated after cataract surgery were $17(60.7 \%)$. In 32 patients who were more than 60 years of age group showing improvement in visual acuity were found to be $13(40.6 \%)$ and those showing fall in visual acuity were $19(59.4 \%)$. 
Table-2: Showing pre -operative and post-operative visual acuity in diabetic and non-diabetic patients as per follow up.

\begin{tabular}{|c|c|c|c|c|c|c|c|}
\hline & \multirow{2}{*}{$\begin{array}{l}\text { NO. of } \\
\text { patients }\end{array}$} & \multirow{2}{*}{$\begin{array}{c}\text { Mean Pre- } \\
\text { operative VA }\end{array}$} & \multicolumn{5}{|c|}{ Mean Post-operative visual acuity in each follow up } \\
\hline & & & $\mathbf{1}^{\text {st }}$ week & $4^{\text {th }}$ week & $6^{\text {th }}$ week & $2^{\text {nd }}$ month & $6^{\text {th }}$ month \\
\hline NPDR & 20 & $6 / 60$ & $6 / 36$ & $6 / 18$ & $6 / 12$ & $6 / 12$ & $6 / 12$ \\
\hline NPDR +ME & 5 & $3 / 60$ & $5 / 60$ & $6 / 60$ & $6 / 36$ & $6 / 36$ & $6 / 36$ \\
\hline PDR & 9 & FCCF & $4 / 60$ & $5 / 60$ & $6 / 60$ & $6 / 60$ & $6 / 60$ \\
\hline PDR+ME & 2 & FCCF & FCCF & FCCF & FCCF & FCCF & FCCF \\
\hline $\begin{array}{l}\text { NO retinopathy } \\
\text { in diabetic }\end{array}$ & 24 & $6 / 36$ & $6 / 12$ & $6 / 9$ & $6 / 9$ & $6 / 6$ & $6 / 9$ \\
\hline $\begin{array}{l}\text { Normal subjects } \\
\text { without diabetes }\end{array}$ & 60 & $6 / 36$ & $6 / 9$ & $6 / 6$ & $6 / 6$ & $6 / 6$ & $6 / 6$ \\
\hline
\end{tabular}

Mean BCVA (best corrected visual acuity) postoperatively was $6 / 36$ in diabetic patients while in non diabetic was $6 / 6$ at 6 months. Majority patients attained BCVA around $6^{\text {th }}$ week. In diabetic patients with retinopathy (36patients) best vision was observed in NPDR patients without macular edema (20 patients) and worst in PDR with macular edema (Finger counting close to face).

Table-3: Showing visual outcome after small incision cataract surgery in patients as per age groups in diabetic group.

\begin{tabular}{|c|c|c|c|}
\hline Age in years & Improved & Worsened & Total \\
\hline$<60$ & $11(39.3 \%)$ & $17(60.7 \%)$ & 28 \\
\hline$>60$ & $13(40.6 \%)$ & $19(59.4 \%)$ & 32 \\
\hline Total & $\mathbf{2 4}$ & $\mathbf{3 6}$ & $\mathbf{6 0}$ \\
\hline
\end{tabular}

There were 06 Patients $(60 \%)$ of less than 5 years of duration of diabetes showing improvement and 04 (40\%) showing fall in visual acuity. There were 3cases having duration of the diabetes between 5 to15 years of which 13(40\%) showed improvement and 18(60\%) got worse. In those cases of more than 15 years duration 14(75\%) cases showed worsening of final best corrected visual acuity and only 5(25\%) cases showed improvement.

Table-4: Showing visual outcome after cataract surgery in patients as per duration of diabetes

\begin{tabular}{|c|c|c|c|}
\hline Duration of DM (in years) & Improved & Worsened & Total \\
\hline$<5$ & $06(60 \%)$ & $04(40 \%)$ & 10 \\
\hline 5 to 15 & $13(40 \%)$ & $18(60 \%)$ & 30 \\
\hline$>15$ & $05(25 \%)$ & $14(75 \%)$ & 20 \\
\hline Total & $\mathbf{2 4}$ & $\mathbf{3 6}$ & $\mathbf{6 0}$ \\
\hline
\end{tabular}

There were 20 cases with NPDR without macular edema of which $8(40 \%)$ cases showed improvement in vision whereas $12(60 \%)$ showed to live up with worse vision. Out of 5 cases of NPDR with macular edema 4(80\%) shown to get worse with visionpostoperatively. Of 9 cases with PDR without macular edema 8 cases $(88.89 \%)$ showed worsening final visual acuity and those with PDR with macular edema showed $100 \%$ worsening of their final best corrected visual acuity.

Table-5: Showing visual outcome after cataract surgery in patients having preoperative diabetic retinopathy in diabetic group

\begin{tabular}{|c|c|c|c|}
\hline Preoperative DR & Improved & Worsened & Total \\
\hline NPDR without ME & $08(40 \%)$ & $12(60 \%)$ & 20 \\
\hline NPDR with ME & $1(20 \%)$ & $04(80 \%)$ & 05 \\
\hline PDR without ME & $1(11.11 \%)$ & $08(88.8 \%)$ & 09 \\
\hline PDR with ME & Nil & $02(100 \%)$ & 02 \\
\hline Total & $\mathbf{1 0}$ & $\mathbf{2 6}$ & $\mathbf{3 6}$ \\
\hline
\end{tabular}


There were variety of post-operative complications after cataract surgery. 21(35.1\%) cases landed up with corneal edema (C.E), 35 (58.3\%) showed iritis postoperatively. $16.6 \%$ of cases had phenomenon of pigment dispersion (PD), 24 $(46.6 \%)$ cases showed posterior capsular opacity (PCO) which is one of the factors responsible for fall in best corrected visual acuity in postoperative period. 25 (41.4\%) showed evidence of anterior capsular contraction (ACC) which was noted on slit lamp examination. There was not a single case found to develop NVG (neovascular glaucoma) and vitreous haemorrhage $\mathrm{VH}$ while $36(60 \%)$ cases shown to develop progression of diabetic retinopathy.

Table-6: Showing various postoperative complications after cataract surgery in diabetic and non diabetic group

\begin{tabular}{|c|c|c|}
\hline Complications & Diabetic group & Non-diabetic group \\
\hline K.edema & $21(35.1 \%)$ & $5(11.62 \%)$ \\
\hline Iritis & $35(58.3 \%)$ & $15(34.8 \%)$ \\
\hline Pigment dispersion & $10(16.6)$ & $2(4.65)$ \\
\hline PCO & $28(46.67 \%)$ & $10(23.25 \%)$ \\
\hline ACC & $25(41.67 \%)$ & $10(23.25 \%)$ \\
\hline Iris prolapse & 1 & 1 \\
\hline VH & Nil & Nil \\
\hline NVG & Nil & Nil \\
\hline
\end{tabular}

Below table gives gross look which states as duration of diabetes increases,postoperativecomplications also increase. There were only 11 complications detected when patients were of less than 5 years duration of diabetes. Those cases between 5 to 10 years duration were detected to develop 40 complications. When the duration of diabetes is more than 15 years a total of 74 complications were noted. In other group of 60 Patients with no diabetes mellitus who undergone small incision cataract surgery.It was found to have corneal edema in 5 cases, 15 cases (34.8\%) showed iritis, only 2 cases $(4.65 \%)$ cases have pigment dispersion, 10 cases $(23.25 \%)$ cases show pco and 10 cases $(23.25 \%)$ showed to have anterior capsular contraction. There was no vitreous haemorrhage

Table-7: Showing postoperative complications according to duration of the diabetes mellitus.

\begin{tabular}{|c|c|c|c|c|c|c|c|c|c|}
\hline $\begin{array}{c}\text { Duration of } \\
\text { DM }\end{array}$ & C.E & Iritis & PD & PCO & ACC & NVG & VH & $\begin{array}{c}\text { Progression of diabetic } \\
\text { retinopathy }\end{array}$ & Total \\
\hline$<5$ & Nil & 4 & Nil & 3 & 2 & Nil & Nil & 2 & 11 \\
\hline 5 to 10 & 02 & 13 & 3 & 8 & 7 & Nil & Nil & 11 & 40 \\
\hline $11 \_15$ & 4 & 5 & Nil & 4 & 4 & Nil & Nil & 8 & 23 \\
\hline$>15$ & 15 & 13 & 7 & 13 & 12 & Nil & Nil & 15 & 74 \\
\hline Total & $\mathbf{2 1}$ & $\mathbf{3 5}$ & $\mathbf{1 0}$ & $\mathbf{2 8}$ & $\mathbf{2 5}$ & Nil & Nil & $\mathbf{3 6}$ & $\mathbf{1 4 8}$ \\
\hline
\end{tabular}

There were 36 cases with diabetic retinopathy diagnosed preoperatively of which $15.89 \%$ become worse at 6 weeks, $33 \%$ at 2 months and $51.2 \%$ at 6 months of follow up showing progression of diabetic retinopathy. There were 24 patients who were not found to have diabetic retinopathy preoperatively of which $14.5 \%$ showed occurrence of diabetic retinopathy at 6 weeks, $32.3 \%$ at 2 months, $53.2 \%$ at 6 months postoperative follow up visit.

\section{Discussion}

The study was aimed to compare postoperative visual outcome and complications after small incision cataract surgery in diabetic patients andnon-diabetic patients who were undergoing small incision cataract surgery. Out of 60 diabetic patients there were 21 male and 39 females with cataract. In othernon-diabetic group out of 60 pts 27 were male and 33 were female. There were $5 \%$ cases diagnosed to have NPDR with macular edema, 20 (55.5\%) NPDR without macular edema, 2 $(3.55 \%)$ cases were with PDR and macular edema and 9 (25\%) were detected to be PDR without macular edema.
In present study there were 20 cases $(55.5 \%)$ having NPDR, 9 cases (25\%) have PDR, and 7 cases (19.3\%) with diabetic maculopathy. The prevalence in the AIOS study was $21.27 \%$ with a range of $12.27 \%$ in the central zone and $34.06 \%$ in the north zone in India [7]. Prevalence of diabetic retinopathy was estimated up to $18 \%$ in urban population of India [8]. In present study it was found consistently that DR was present in cases having duration of diabetes more than 15 years. Most of studies on DR shows that the best predictor of DR is duration of diabetes. In short prevalence of diabetic 
retinopathy is positively associated with duration of diabetes. Ronald Klein at al found that duration of diabetes is strongly associated with frequency and severity of diabetic retinopathy. Their study showed $77.8 \%$ of prevalence of diabetic retinopathy when duration of diabetes was 15 years or more and $2 \%$ prevalence of PDR when duration is 5 years[9]. Muhammad Khizar Niazi showed duration of diabetes remained the strongest predictor for any diabetic retinopathy as well as its severity. Patients with duration 5-10 years had 5 times more chances to have nonproliferative retinopathy and $2 \times 10^{6}$ times more chances for advance retinopathy than patients with duration less than 5 years and no retinopathy [10].

In present study outcome was found to be poor as duration of diabetes increases, this may be due to increased incidence of complications that were observed with increase in duration of diabetes or it may be due to presence or progression of diabetic retinopathy postoperatively. In present study $75 \%$ (14 cases) shown to become worse postoperatively who were having duration of the diabetes mellitus more than 15 years. Those cases of PDR with macular edema (100\%) and $80 \%$ with NPDR with macular edema became worse postoperatively in our study.

In present study iritis was found to be $58.3 \%$ in diabetic group as compared to $34.8 \%$ in non-diabetic group. Takamura $y$ et al had shown thatanterior segment inflammation as measured by an increase aqueous flare intensity to be significantly increased in diabetic patients with DR as compared to non-diabetic patients [11]. According to Hreidarsson A.B non-dilatation of pupil due to diabetic autonomic neuropathy affects the sympathetic innervations to the dilator muscle [12].

This rigidity of iritis can be one of the reasons for iritis in diabetics. In present study $46.67 \%$ (28 cases) develop posterior capsular opacification in diabetic group. In non-diabetic group 10 cases $(23.25 \%)$ found to develop PCO. According to study by Ken Hayashi at alin diabetic, PCO was found to be consistent finding involving peripheral portion of capsule [13].

Knorz MC et al showed posterior capsule opacification (PCO) after cataract surgery in diabetic patients is more extensive than in nondiabetic patients[14]. Our study showed similar result with PCO rate more in diabetic.

Lloyd $\mathrm{M}$ et al showed intracapsular cataract extraction in diabetic population, without regard of the preoperative status of the retinopathy, was associated with a statistically significant incidence of postoperative rubeosis iridis/neovascular glaucoma [15] while Townes CD, Casey ER and Cramer FK do not mention rubeosis iridis/ neovascular glaucoma at all as a postoperative complication [16][17]. In our study too there was not a single case of $\mathrm{NVG}$ or vitreous hemorrhage. Earlier studies of Lloyd $\mathrm{M}$ et al showing NVG after cataract surgery may be contributed to the intracapsular cataract extraction technique.

Also in present study from diabetic group only 2 cases had vitreous loss following rupture of posterior capsule (PCR) of lens. Among non-diabetic group not a single case of PCRnoted among non-diabetic group. Chitkara et al found that diabetes mellitus increased the risk of VL [18]. Ninn-Pedersen K, Stenevi U showed presence of diabetes mellitus and vitreous loss due o PCR did not significantly correlated [19].

Lumme P, Laatikainen LT showed similar result [20]. In current study only 2 cases develop vitreous loss as complication may be due to improvement in techniques of cataract surgery.

Summary and conclusion: The study was conducted to aim to observe visual outcome and postoperative complications after small incision cataract surgery in diabetic and non-diabetic group. Cataract surgery in diabetic group gives good results provided patients diabetic status is under good control and needs to be operated in early stages of DR for better results.

Recommendations: Small incision cataract surgery gives as good result in diabetic patients as that of non diabetic patients provided diabetes should be under good control pre and postoperatively and if operated at early stages of diabetic retinopathy.

Current study adding to existing knowledge: Small incision cataract surgery is a safe and economical method even in diabetes patients and can be consider as safe procedure for diabetic patients in developing countries having lack of access to health care,provided diabetes should be under good control pre and postoperatively.

Footnote: Grant support and financial disclosure: None

\section{Authors contributions}

Aparna. K: Concieved, designed, Statistical analysis and manuscript writing, Snehal. R: Literature search and editing of manuscript.

Aparna. K: Did review and final approval of manuscript 


\section{Funding: Nil, Conflict of interest: Nil Permission from IRB: Yes}

\section{References}

1. Threatt J, Williamson JF, Huynh K, et al. Ocular disease, knowledge and technology applications in patients with diabetes. Am J Med Sci. 2013 Apr;345 (4):266-270. doi:10.1097/MAJ.0b013e31828aa6fb

2. Cunliffe IA Flanagan DW, George NDL, Aggrawal RJ, Moore AT. Extracapsular cataract extraction with lens implantation in diabetics with or without proliferative retinopathy.Br J Ophthalmo1991;75(1):9 -12.

3. Klein BE, Klein R, Moss SE. Incidence of cataract surgery in the Wisconsin Epidemiologic Study of Diabetic Retinopathy. Am J Ophthalmol. 1995 Mar;119 (3):295-300.

4. Krupsky S, Zalish M, Oliver M, Pollack A. Anterior segment complications in diabetic patients following extracapsular cataract extractionand posterior chamber intraocular lens implantation. Ophthalmic Surg. 1991 Sep; 22(9):526-30.

5. Zaczek A, Olivestedt G, Zetterström C. Visual outcome after phacoemulsification and IOL implanttation in diabetic patients. Br J Ophthalmol. 1999 Sep; 83(9):1036-41.

6. Tabin G, Chen M, Espandar L. Cataract surgery for the developing world. OpinOphthalmol. 2008 Jan;19 (1): 55-9. doi:10.1097/ICU.0b013e3282f154bd

7. Gadkari SS, Maskati QB, Nayak BK. Prevalence of diabetic retinopathy in India: The All India Ophthalmological Society Diabetic Retinopathy Eye Screening Study 2014. Indian J Ophthalmol. 2016 Jan;64 (1):3844. doi:10.4103/0301-4738.178144.

8. Raman R, Rani PK, ReddiRachepalle S, et al. Prevalence of diabetic retinopathy in India: Sankara Nethralaya Diabetic Retinopathy Epidemiology and Molecular Genetics Study report 2. DOI:10.1016/j. ophtha.2008.09.010Ophthalmology.2009 Feb;116(2): 311-8.

9. Klein R, Klein BE, Moss SE, et al. The Wisconsin epidemiologic study of diabetic retinopathy. II. Prevalence and risk of diabetic retinopathy when age at diagnosis is less than 30 years. Arch Ophthalmol. 1984 Apr;102(4):520-6.

10. Niazi KM, Akram A, Naz AM, Awan S. Duration of diabetes as a significant factor for retinopathy. Pak J Ophthalmol. 2010;26(4):182-87.

11. Takamura $\mathrm{Y}$, Tomomatsu $\mathrm{T}$, Arimura $\mathrm{S}$, et al. Anterior capsule contraction and flare intensity in the early stages after cataract surgery in eyes with diabetic retinopathy. J Cataract Refract Surg 2013;39(5):716-21.

12. Hreidarsson AB. Pupil motility in long-term diabetes. Diabetologia. 1979 Sep;17(3):145-50.

13. Hayashi K, Hayashi H, Nakao F, Hayashi F. Posterior capsule opacification after cataract surgery in patients with diabetes mellitus. Am J Ophthalmol. 2002 Jul;134(1):10-6.

14. Knorz MC, Soltau JB, Seiberth V, Lorger C. Incidence of posterior capsule opacification after extracapsular cataract extraction in diabetic patients. MetabPediatrSystOphthalmol1991;75:9-12.

15. Aiello LM, Wand M, Liang G. Neovascular glaucoma and vitreous hemorrhage following cataract surgery in patients with diabetes mellitus. Ophthalmology. 1983 Jul;90(7):814-20.

16. Townes CD, Casey ER. Cataract surgery in diabetic patients. South Med J. 1955 Aug;48(8):844-6.

17. Cramer FK. Operative complications of cataract extraction in diabetics. Int Ophthalmol Clin. 1963 Sep; 3: $645-56$

18. Chitkara DK, Smerdon DL. Risk factors, complications, and results in extracapsular cataract extraction. J Cataract Refract Surg. 1997 May;23 (4): $570-4$.

19. Ninn-Pedersen K, Stenevi U. Cataract surgery in a Swedish population: observations and complications. J Cataract Refract Surg. 1996 Dec; 22 (10):1498505.

20. Lumme P, Laatikainen LT. Risk factors for intraoperative and early postoperative complications in extracapsular cataract surgery. Eur J Ophthalmol. 1994 Jul-Sep;4(3):151-8.

\section{How to cite this article?}

Kekan A, Raut S. Comparative study of post-operative visual outcome and complications after small incision cataract surgery in patients of diabetic and non-diabetic patients of cataract. Trop J Ophthalmol Otolaryngol.2018;3(3):27-32. doi: 10.17511/jooo.2018.i03.04 